\title{
REALIZAÇÃO DE UM SONHO: O SIGNIFICADO CULTURAL DA GRAVIDEZ PARA GESTANTES ADOLESCENTES
}

\section{COMPLETION OF A DREAM: THE CULTURAL MEANING OF PREGNANCY FOR PREGNANT TEENAGERS}

\section{REALIZACIÓN DE UN SUEÑO: EL SIGNIFICADO CULTURAL DEL EMBARAZO PARA ADOLESCENTES EMBARAZADAS}

\author{
Carolina Carbonell Demori ${ }^{1}$, Lisie Alende Prates ${ }^{2}$, Natália da Silva Gomes ${ }^{3}$, Carolina Heleonora \\ Pilger $^{4}$, Luiza Cremonese 5 , Camila Nunes Barreto ${ }^{6}$
}

Como citar esse artigo: Demori CC, Prates LA, Gomes NS, Pilger CH, Cremonese L, Barreto CN. Realização de um sonho: o significado cultural da gravidez para gestantes adolescentes. Rev Enferm Atenção Saúde [Internet]. 2021 [acesso em ];10(1):e202111. doi:10.18554/reas.v10i1.4233

\section{RESUMO}

Objetivo: compreender o significado cultural da gravidez para gestantes adolescentes. Método: trata-se de um estudo de campo, qualitativo, realizado em uma Unidade Básica de Saúde da cidade de Santa Maria/RS, entre fevereiro e maio de 2012. Participaram da pesquisa oito gestantes adolescentes que faziam pré-natal na unidade. A entrevista narrativa foi utilizada na coleta dos dados. O estudo foi aprovado pelo Comitê de Ética em Pesquisa da Universidade Federal de Santa Maria sob o número do CAAE 00554512.0.0000.5346. Resultados: a partir da análise dos dados emergiram duas categorias: "Sentimentos vividos pelas adolescentes na gravidez" e "Prefiro ser mãe". As gestantes adolescentes consideram a gravidez como a realização de um sonho. Conclusão: a gravidez nesta etapa de vida pode ser uma escolha individual, e é preciso que esta realidade seja compreendida e desmistificada pela sociedade moderna, principalmente pelos profissionais da saúde.

Descritores: Enfermagem; Cultura; Gravidez na adolescência.

\footnotetext{
${ }^{1}$ Enfermeira. Especialista em Cuidado Pré-Natal e em Ginecologia e Obstetrícia. Doutora em Ciências da Saúde. Enfermeira do Hospital de Guarnição de Bagé. Bagé-RS. http://orcid.org/0000-0002-5153-549X, carolinacdemori@gmail.com

Enfermeira. Doutora em Enfermagem. Especialista em Enfermagem em Cuidado Pré-Natal e em Enfermagem Obstétrica. Professora Adjunta da UNIPAMPA, campus Uruguaiana. Líder do Grupo de Pesquisas GRUPESM, da UNIPAMPA. Uruguaiana RS. http://orcid.org/0000-0002-5151-0292, lisiealende@ hotmail.com

3 Acadêmica do curso de Enfermagem da UNIPAMPA, campus Uruguaiana/RS. Bolsista do PET-PISC. Integrante do Grupo de Pesquisas GRUPESM. Uruguaiana-RS. http://orcid.org/0000-0002-6952-7172, nataliasilvag_@hotmail.com

4 Acadêmica do curso de Enfermagem da UNIPAMPA, campus Uruguaiana/RS. Bolsista do PET-PISC. Integrante do Grupo de $\quad$ Pesquisas http://orcid.org/0000-0001-6844-962X, carolinapilger@gmail.com

${ }^{5}$ Enfermeira. Especialista em Saúde Pública com ênfase em Saúde da Família e em Saúde do Adolescente. Doutoranda em Enfermagem da UFSM. Professora do Curso de Graduação em Enfermagem na Universidade Luterana do Brasil - Campus Cachoeira do Sul (ULBRA). Integrante do Grupo de Pesquisa PEFAS/UFSM. Universidade Luterana do Brasil - Cachoeira do Sul http://orcid.org/0000-0001-7169-1644, lu_cremonese@ hotmail.com

${ }^{6}$ Enfermeira. Doutoranda em Enfermagem da UFSM. Enfermeira da Secretaria Estadual de Saúde do Rio Grande do Sul, lotada na $8^{\text {a }}$ Coordenadoria Regional de Saúde de Cachoeira do Sul. Cachoeira do Sul - RS. http://orcid.org/0000-0001-5638-550X, camilabarreto_6@msn.com
} 


\begin{abstract}
Objective: to understand the cultural meaning of pregnancy for pregnant adolescents. Method: this is a qualitative field study, conducted in a Basic Health Unit in the city of Santa Maria / RS, between February and May 2012. Eight adolescent pregnant who attended prenatal care in the unit participated in the research. The narrative interview was used to collect data. The study was approved by the Research Ethics Committee of the Federal University of Santa Maria under number CAAE 00554512.0.0000.5346. Results: from the data analysis emerged two categories: "Feelings experienced by adolescents in pregnancy" and "I prefer to be a mother". Teenage pregnant consider pregnancy to be a dream come true. Conclusion: pregnancy at this stage of life can be an individual choice, and this reality must be understood and demystified by modern society, especially health professionals.
\end{abstract}

Descriptors: Nursing; Culture; Pregnancy in adolescence.

\title{
RESUMEN
}

Objetivo: comprender el significado cultural del embarazo para adolescentes embarazadas. Método: estudio de campo cualitativo, realizado en una Unidad Básica de Salud de la ciudad de Santa Maria/RS, entre febrero y mayo de 2012. En la investigación, participaron ocho adolescentes embarazadas que recibían atención prenatal en la unidad. La entrevista narrativa se utilizó para recopilar datos. El estudio fue aprobado por el Comité de Ética en Investigación de la Universidad Federal de Santa María bajo el número CAAE 00554512.0.0000.5346. Resultados: del análisis de datos surgieron dos categorías: "Sentimientos experimentados por las adolescentes en el embarazo" y "Prefiero ser madre". Las adolescentes embarazadas consideran que el embarazo es un sueño hecho realidad. Conclusión: el embarazo en esta etapa de la vida puede ser una elección individual, y esta realidad debe ser entendida y desmitificada por la sociedad moderna $\mathrm{y}$, en especial, por los profesionales de la salud.

Descriptores: Enfermería; Cultura; Embarazo en la adolescencia.

\section{INTRODUÇÃO}

Independente das delimitações etárias da adolescência é necessário compreendê-la como uma maneira de viver construída historicamente, condicionada pelas particularidades dos diferentes meios sociais e culturais que são conformados em uma realidade múltipla e complexa. ${ }^{1}$ Ao invés de se olhar a adolescência estritamente como uma "fase e campo de riscos", devemos entender o conceito de vulnerabilidades, pelo qual os riscos estão diretamente associados a fatores individuais, familiares, culturais, sociais, políticos, econômicos e biológicos. ${ }^{2}$
Compreende-se que ao chegar à adolescência, o ser humano sofre várias transformações para atingir a maturidade, dentre elas, destaca-se, neste estudo, as relativas à sexualidade que podem levar ao surgimento da gravidez na adolescência. Essas transformações, muitas vezes, geram conflitos, dúvidas e expõem a adolescente pela vulnerabilidade própria desta fase da vida. Nesta, descobre-se o sexo, mas faltam orientações e acompanhamento que façam a adolescente compreender sua sexualidade, e vivenciar essa etapa de vida com segurança. ${ }^{3}$ 
A gestação na adolescência é uma realidade em nossa sociedade, e é consequente a fatores como a falta de uma política de atenção específica e eficaz nesta faixa etária, da ausência de educação sexual nas escolas, da falta de programas de planejamento familiar nos serviços públicos de saúde, entre outros. ${ }^{4}$

Além disso, alguns autores afirmam que há alguns fatores de risco iminentes para a ocorrência da gravidez na adolescência, como início precoce da vida sexual, níveis de escolaridade e sócio econômicos baixos e desconhecimento da estrutura fisiológica reprodutiva, como a capacidade de identificação do período fértil. ${ }^{5}$

O desejo de ser mãe, muitas vezes, impulsiona a adolescente a vivenciar essa experiência em sua concretude, o que faz com que ela planeje sua gravidez, ou, não tome precauções para que ela seja impedida. Algumas vezes, a emergência de ter um filho pode ser influenciada pelo companheiro, o que faz aflorar à vontade, do que não era planejado para aquele momento. ${ }^{6}$

Nesse sentido, a inclusão das adolescentes nas políticas de saúde, especialmente naquelas voltadas para a saúde sexual e saúde reprodutiva, requer novas perguntas sobre a realidade destes sujeitos. É imperioso que tais perguntas sejam feitas a estes, respeitando e considerando seus olhares, opiniões, propostas e condições sociais do meio em que vivem. A capacidade criativa e o potencial de participação social devem ser resguardados e promovidos nas práticas e políticas de saúde, assim como pelas demais políticas sociais. $^{7}$

Percebe-se, no entanto, que há muito a ser estudado no que se refere às questões relativas à gravidez na adolescência, sendo necessária a compreensão dessa temática como forma de contribuir à implementação de estratégias contextualizadas e efetivas na realidade dos serviços de saúde. Da mesma forma, a busca pelo conhecimento nessa área poderá refletir em possibilidades de empoderamento dos sujeitos envolvidos, representando a oportunidade desses virem a ser agentes de transformação de sua realidade social.

Este estudo teve como objetivo compreender o significado cultural da gravidez para gestantes adolescentes.

\section{MÉTODO}

Trata-se de um estudo de campo, com abordagem qualitativa, desenvolvido no período de março a julho de 2012. Em relação à abordagem qualitativa, ${ }^{8}$ acreditase que esta permitiu a sustentação deste estudo, considerando que possibilitou além de uma interpretação com lentes ampliadas à singularidade do objeto de estudo - 
experiência de ser mãe adolescente -, uma inserção na cultura do "outro".

As participantes foram oito gestantes adolescentes que faziam acompanhamento pré-natal na Unidade Básica de Saúde (UBS). As gestantes adolescentes foram convidadas a participar do estudo na consulta de pré-natal, uma vez que a amostra foi intencional, sendo os participantes determinados pelo objetivo do estudo. ${ }^{8}$

O cenário escolhido para o desenvolvimento do estudo foi a região norte da cidade de Santa Maria/RS, onde está localizada a Unidade Sanitária Kennedy (USK). Esta apresenta uma série de problemáticas relacionadas às desigualdades sociais, dentre elas altos índices de desemprego, violência, tráfico de drogas, desnutrição, doenças infectocontagiosas, precariedade de saneamento básico e habitação. A condição de pobreza é a realidade da maioria dos moradores da região.

Considerando o percurso metodológico, a narrativa ${ }^{9}$ foi a estratégia utilizada para a realização das entrevistas na produção de dados, permitindo aproximarse da experiência narrada pelas adolescentes de maneira que elas não informassem, mas contassem suas experiências favorecendo a compreensão sobre o significado cultural da gestação em suas vidas.
Assim, as narrativas revelam-se como possibilidade para compreender e comunicar experiência humana subjetiva, enfatizando o significado, o processo de produzir histórias, as relações entre o narrador e os demais participantes, os processos de conhecimento e a multiplicidade de formas para captar e compreender a experiência. ${ }^{9}$ As entrevistas narrativas foram realizadas individualmente, conforme agendamento com as gestantes no momento das suas consultas de pré-natal, em local e horário definidos por elas, ocorrendo tanto no domicílio e na UBS. A coleta de dados foi audiogravada, conforme consentimento/assentimento das participantes, e na sequência, transcrita para análise.

Adotou-se para análise dos dados, a análise temática, a qual consiste em descobrir os núcleos de sentidos que constituem uma comunicação em que a frequência ou presença possuam algum significado para o objeto analítico. A análise temática é constituída por três etapas: a pré-análise, a exploração do material e o tratamento dos resultados obtidos e interpretação. ${ }^{10}$

Foram observadas as normas da Resolução n 196/96 do Conselho Nacional de Saúde do Ministério da Saúde, que dispõe sobre diretrizes e normas regulamentares da pesquisa envolvendo a 
participação de seres humanos. O projeto desta pesquisa foi submetido à autorização da Secretaria Municipal de Saúde de Santa Maria (SMSSM); registrado na Plataforma Brasil, sob CAAE número 00554512.0.0000.5346, e encaminhado para apreciação e aprovação do Comitê de Ética e Pesquisa da UFSM (CEP). Foi providenciado às participantes $\mathrm{O}$ conhecimento e a assinatura do Termo de Consentimento Livre e Esclarecido, que foi assinado pelo responsável em caso de menores de 18 anos. Nestes casos, a participante também assinou o Termo de Assentimento.

\section{RESULTADOS}

Os resultados são apresentados nas seguintes categorias e seus componentes: Sentimentos vividos pelas adolescentes na gravidez e "Prefiro ser mãe".

As narrativas demonstram que a gestação, para muitas adolescentes é um sonho ou uma perspectiva de vida, sendo natural, esperado e planejado. Para estas adolescentes, a maternidade aparenta ser uma forma de realização pessoal, o plano de vida ao qual a adolescente vai ao encontro.

\section{Sentimentos vividos pelas adolescentes na gravidez}

Para estas adolescentes, a maternidade aparenta ser uma forma de realização pessoal, o plano de vida ao qual a adolescente vai ao encontro.

Acho que em relação a mim e o meu namorado, é uma coisa para parar as brigas sabe, porque a gente brigava muito, eu batia de frente, nossos gênios não são fáceis. O bom é que agora nós conversamos bastante. Ele sempre me fala que vou ser uma mãe boa, a gente entrou num acordo, eu achava que eu não queria a mesma coisa que eu, mas nós queremos a mesma coisa (A7, 16 anos).

Minha vida hoje é bem diferente do que era antes. Acho que agora fiquei mais responsável, imagina, meu filho ou filha, porque não sei ainda se é guri ou guria, vai precisar de mim, e não quero que ele tenha uma mãe irresponsável. Eu não falto mais a aula, porque antes eu nunca ia, ficava na rua até tarde e matava aula (A2, 18 anos).

Quero dar uma vida melhor pra ele (bebê), tranquila, feliz, quero estar perto, dar carinho pra ele. Acho que vai ser bom pra ele, sempre vai ter alguém do meu lado e dele. A gente sempre vai estar juntos. Já penso em ter outros filhos, ou esse vai ser o último, não sei, está na mão de Deus (A3, 19 anos).

Ser mãe significa uma forma de se colocar no mundo como sujeitos sociais. Antes eram apenas meninas, e passaram a serem mulheres que têm seus companheiros fixos, suas casas, suas responsabilidades, conforme vê-se nas falas, a seguir: 
Eu prefiro ter a criança a ficar saindo por aí de noite que nem as outras. Prefiro ser mãe mesmo, é mais responsabilidade (A5, 13 anos).

Mas eu vou procurar trabalhar bastante para poder dar um futuro melhor pra ela, para dar pra ela uma infância que eu não tive (A6, 17 anos).

Agora sei que tenho que me cuidar, não posso ficar saindo para dançar e beber como eu fazia, eu saía bastante, bebia (A8, 19 anos).

Percebe-se, também, que algumas adolescentes demonstraram aumento da sensibilidade e certa ambivalência de sentimentos, fato comum nesse período da vida, repleto de transformações fisiológicas e emocionais, como se percebe por meio destas respostas:

Daí depois que deu positivo eu chorava porque sentia um pouco de medo, por causa do meи pai, e porque também estava feliz. Sentia as duas coisas (A5, 13 anos).

Foi um susto para mim, eu senti tudo ao mesmo tempo. Todos os sentimentos possíveis. Me senti feliz, pensei que não era verdade. Me senti apavorada. Tudo que tu pode imaginar ao mesmo tempo, porque era eu que aconselhava as outras, dizia “cuidado com a barriga” ( $A 7$, 16 anos).

Outras adolescentes relataram algumas dificuldades no momento da descoberta da gravidez, a sensação da nova responsabilidade e de anunciar a gravidez aos parceiros. Percebe-se, também, o apoio destes e o sentimento de alívio para elas:

Na verdade, quase caí pra trás né? Eu estava com bastante dor na barriga. Daí fui fazer um ultrassom, estava sozinha. Fiquei muito nervosa. Eu não estava planejando, estava muito cedo ainda. Nós estávamos alugando casa ainda né? Depois ele ficou mais feliz que eu (A1, 16 anos).

Daí com esses dois exames de farmácia que deram positivo que fiz em casa sozinha, eu sentava, conversava com Deus, agradecia, mas eu chorava muito. Quando ele soube, ele ficou muito feliz, então foi aí que eu fiquei mais alegre sabe, deu um alívio, me senti mais confortada. Daí sim eu quis assumir essa gravidez (A2, 18 anos).

Eu não tive a sensação de dar a notícia de dizer "amor senta que quero te dar uma notícia”: - “eu to grávida”. Era o que mais queria fazer, tipo filme, novela. Foi bem chato essa parte, sofri bastante. Eu estou muito feliz, às vezes dá aquela coisa assim que poderia estar aproveitando minha vida de outra maneira, mas aí eu paro, penso, boto a mão na minha barriga, sinto ela, o vejo falando com ela, é outra coisa. Daí eu já entro em outra realidade e viro outra (A6, 17 anos).

Foi difícil, no começo foi porque eu não queria, é muita responsabilidade, daí 
tive que aceitar, mas agora é tudo que eu quero. Acho que deu uma alegria, agora eu estou mais feliz. Eu era muito tímida antes, muito fechada. Agora falo mais, tenho mais sobre o que falar, me sinto muito feliz. Ter uma pessoa dentro de ti é bem diferente. Pra mim foi uma grande coisa (A8, 19 anos).

\section{"Prefiro ser mãe"}

Um dos aspectos evidenciados é o fato de que a adolescente, ao engravidar, pode estar realizando um sonho. E esta decisão, que contempla não apenas um ato biológico reprodutivo, mas um processo social envolvendo interações com seus familiares, seu companheiro e, ainda, a vontade de vir a ser mãe e ingressar no mundo adulto, conforme se verifica nos fragmentos das narrativas:

Eu me sinto mais mulher menos guria sabe, parece que eu sou outra. Fui criando um sentimento de mãe que eu não sei explicar, é uma coisa que acho que só quem é mãe sabe. É uma coisa muito forte e incondicional (A2, 18 anos).

Não é porque eu sou nova que não posso ser mãe (A4, 17 anos).

Eu prefiro ter a criança a ficar saindo por aí de noite que nem as outras. Prefiro ser mãe mesmo, é mais responsabilidade (A5, 13 anos).

Para algumas adolescentes, a gravidez vem permeada de boas expectativas, pois desde a sua descoberta, as mães começam a planejar o futuro.

Meus planos para o futuro é cuidar do meu filho, estamos procurando outra casa para alugar, menor que aquela que é muito grande (A1, 16 anos).

Mas quero minha mãe perto para me ajudar, porque sei que não é fácil criar uma criança. E depois ainda pode vir outra, vai saber. Agora nós estamos ali na mãe para conseguir juntar dinheiro e fazer nossa casa (A4, 17 anos).

\section{DISCUSSÃO}

Os sentimentos positivos em relação à maternidade predominaram sobre os negativos, porque a qualidade de vida destas adolescentes havia melhorado. O sentimento de vazio que existia em relação à vida, à incorporação do papel materno, à obtenção de uma razão para viver, o sentimento de autoconfiança, à responsabilidade para continuar vivendo, e à sensação de pertencer a uma família, foram alguns dos aspectos positivos mencionados pelas adolescentes.

Dentro desta perspectiva, em seu estudo, autoras ${ }^{12}$ ressaltam que prevalece, em nossa cultura, a representação da maternidade como algo positivo e socialmente valorizado. Por isso, é fundamental que, ao buscar conhecer as representações acerca da gravidez na adolescência, atente-se para o fato de que as 
representações dos sujeitos se mostram como um produto social, ou seja, as adolescentes elaboram suas representações sobre a gravidez na adolescência a partir de seu contexto social.

Muitas adolescentes mudaram seu estilo de vida após a incorporação do papel materno. Elas se distanciaram dos amigos e deixaram a "vida na rua" para destinar mais atenção aos seus filhos. Foram mudanças avaliadas de forma positiva para elas.

Outro fator relevante que explica a felicidade das adolescentes por terem engravidado, ainda segundo um estudo, ${ }^{13}$ é a possibilidade da constituição de uma família, mesmo em condições precárias e em uma fase precoce da vida, pois ter uma casa para morar e o controle sobre a situação, representava a possibilidade da liberdade para fazer tudo o que não era possível fazer, morando na casa dos pais ou dos parentes.

Em algumas sociedades, inclusive, é esperado da mulher que já saiu da casa dos pais para morar com o parceiro que, após um período de união estável, constituem uma família com filhos, independente das condições econômicas ou da maturidade do casal. O próprio estudo do Instituto de Pesquisa Econômica Aplicada ${ }^{12}$ levanta a possibilidade de que a maternidade, entre as adolescentes brasileiras, seria uma estratégia para elevar seu papel social, uma vez que a maternidade é um papel social valorizado.

Nas narrativas, percebe-se esta ambivalência afetiva na oscilação entre o desejo e o não desejo da gestação, o querer e o não-querer da criança. Não há uma aceitação total ou rejeição total da gravidez, pois como refere um estudo, ${ }^{13}$ o sentimento oposto jamais estará inteiramente ausente.

No entanto, nota-se que, vários eventos associados, como o desconhecimento dos pais quanto ao início da atividade sexual, a dependência emocional e afetiva, o processo de formação da personalidade adulta e outras características comuns ao período da adolescência, potencializam sentimentos, como medo, insegurança, angústia e ansiedade.

Ao referirem o aumento de responsabilidades, percebe-se, assim como em outro estudo ${ }^{14}$ nesta temática, que parece há uma busca de estabilidade revelada por meio da percepção do filho como algo próprio, um bem. Isto pode revelar uma tentativa de obter autonomia, atingir a maturidade e perceber sua própria competência para cuidar do filho.

Percebe-se, também, a falta de experiência em desempenhar o papel de mãe. As verbalizações referem-se às dificuldades e insegurança no processo de cuidar da criança. É preciso compreender que os assuntos relacionados à transição ao 
papel materno não podem ser associados apenas às questões biológicas, mas também às questões sociais e emocionais, pois a complexidade do fenômeno da transição não envolve apenas a adolescente, mas toda sua rede de relacionamentos.

Para minimizar as dificuldades que a maternidade traz, se faz necessário que a mulher construa suportes alicerçados em conhecimento, responsabilidade, criatividade, segurança, amor, carinho, compreensão e sincronismo, para o seu ajustamento à maternidade.

Quando se tratam de adolescentes, com escassas condições financeiras para planejamentos de um crescimento profissional, estas podem buscar suas satisfações pessoais naquilo que consideram como uma construção pessoal passível de concretização. Assim, o reconhecimento social como sujeito produtivo, pode ocorrer através da concepção de um filho, na maternidade.

A literatura aponta que a gravidez na vida de uma mulher não se verifica de modo aleatório e, sim, por prioridades preestabelecidas, isto é, elaboração de planos, projetos ou pela concretização da prática sexual, já que conhecem os métodos contraceptivos para evitar a gravidez. ${ }^{15}$

As adolescentes aspiram constituir um novo lar, caracterizando uma independência de suas famílias de origem. Contudo, uma das adolescentes apontou a necessidade de que sua nova casa esteja próxima a de sua família, demonstrando dependência emocional em relação a esta.

Para a adolescente, a realização do desejo de uma nova casa pode significar a concretização de sua representação como um indivíduo adulto e autônomo, além de sua capacidade como mãe de oferecer ao filho subsistência e um ambiente propício ao seu desenvolvimento, independente da composição estrutural de sua família de origem.

\section{CONCLUSÃO}

Percebe-se que as adolescentes constroem sua identidade de mãe, a partir de sua vivência gestacional e da construção de uma identidade de mulher-mãe. O estudo demonstra, também, que a sociedade vem sofrendo mudanças ao longo do tempo e que estas vêm influenciando as representações acerca da maternidade, evidenciando a existência de elementos como o desejo de ser mãe, mesmo sendo adolescente.

Nota-se que tanto as famílias quanto os parceiros das adolescentes são apoiadores da gravidez, mesmo que, primeiramente, a descoberta da gravidez cause dúvida e ansiedade às adolescentes. Apesar de a gravidez na adolescência se caracterizar, no sentido geral, como advento fora de hora e atrelado a outros constituintes de conotação negativa, ela também é 
elaborada e percebida pelas adolescentes como evento gerador de condicionantes positivos.

Evidencia-se, assim, uma dualidade inerente ao ser adolescente do sexo feminino de classes mais populares, que apesar de repetir um discurso social de inadequação e incompatibilidade entre a gravidez e a adolescência, tem a gestação representada com naturalidade. Os significados que a gestação possui, na vida dessas adolescentes, foram representados no relato de sentimentos que envolviam amor, felicidade e responsabilidade.

Como limitações do estudo, considera-se que o significado cultural da gravidez evidenciado representa a perspectiva de um grupo de gestantes adolescentes, com características específicas e pertencentes a um contexto sociocultural, não podendo, assim, ser generalizado a todo o universo de indivíduos que vivencia a gestação na adolescência. Para tanto, propõe-se que novos estudos sejam desenvolvidos, contemplando gestantes adolescentes de outros contextos e com outras características. Além disso, salienta-se que o número reduzido de participantes se deu em função da dificuldade em acessá-las e captá-las para participação na pesquisa, tendo em vista o fato de que as gestantes adolescentes apresentavam elevada abstenção às consultas de pré-natal.
Apesar disso, entende-se que a interpretação dos dados coletados, nesta pesquisa, possa colaborar na construção de subsídios que possibilitem reflexões singulares sobre a vivência da gravidez na adolescência como uma escolha individual, permitindo além da desconstrução e da reconstrução de conceitos, afastar preconceitos e tensões que permeiam essa temática, apesar desta ainda assumir estereótipos de problema social, desordem comportamental ou irresponsabilidade. Ainda, pensa-se contribuir para que este tema, na formação dos profissionais da saúde, seja encarado e percebido como uma realidade que deve ser aceita, compreendida e trabalhada por todos.

\section{AGRADECIMENTOS}

Fundo de Incentivo à Pesquisa (FIPE)/Universidade Federal de Santa Maria (UFSM)

\section{REFERÊNCIAS}

1. Fiedler MW, Araújo A, Souza MCC. A prevenção da gravidez na adolescência na visão de adolescentes. Texto \& Contexto Enferm. [Internet]. 2015 [citado em 23 jun 2020]; 24(1):30-7. Disponível em: https://www.scielo.br/j/tce/a/VJpfBML95 m99849vyStb7Tt/abstract/?lang=pt 2. Araújo DHQ, Araújo SS, Rabelo AL, Santos JS, Lima PS, Coelho KR. Fatores associados a qualidade de vida de adolescentes vinculados a uma equipe de saúde da família. Adolesc Saúde [Internet]. 2020 [citado em 23 jun 2020]; 17(1):2534. Disponível em: 
https://cdn.publisher.gn1.link/adolescencia esaude.com/pdf/v17n1a04.pdf

3. Turke KC, Ribeiro PA, Sando C, Antonio GL, Teodoro VC, Reato LFN. Atividade educativa em saúde sexual e reprodutiva para meninas em situação social de risco. Adolesc Saúde [Internet]. 2019 [citado em 23 jun 2020]; 16(3):1722. Disponível em:

https://cdn.publisher.gn1.link/adolescencia esaude.com/pdf/v16n3a03.pdf

4. Sfair SC, Bittar M, Lopes RE. Educação sexual para adolescentes e jovens: mapeando proposições oficiais. Saúde Soc, [Internet]. 2015 [citado em 23 jun 2020]; 24(2):620-32. Disponível em: https://www.scielo.br/j/sausoc/a/Bwt8Jny mQL5zc9PHRrj6P4y/abstract/?lang=pt 5. Alves H, Brito IS, Silva TR, Viana AA, Santos RCA, Oliveira CPB. Fatores intervenientes da gravidez na adolescência a partir de um modelo de promoção da saúde baseado na comunidade. Adolesc Saúde [Internet]. 2020 [citado em 23 jun 2020]; 17(1):8-17. Disponível em: https://cdn.publisher.gn1.link/adolescencia esaude.com/pdf/v17n1a02.pdf

6. Fernandes RFM, Meincke SMK, Soares MC, Bueno MEN, Corrêa ACL, Alves CN. Maternidade na adolescência: motivos para planejá-la. Rev Enferm UFPE on line [Internet]. 2017 [citado em 23 jun 2020]; 11(5):1776-82. Disponível em: https://periodicos.ufpe.br/revistas/revistaen fermagem/article/view/23322/18908 7. Ministério da Saúde (Brasil), Secretaria de Atenção à Saúde, Departamento de Ações Programáticas Estratégicas. Marco teórico e referencial: saúde sexual e saúde reprodutiva de adolescentes e jovens. Brasília: Editora do Ministério da Saúde; 2006.

8. Leopardi MT. Metodologia da pesquisa da saúde. Santa Maria, RS: Pallotti; 2001. 9. Silva DGV, Trentini M. Narrativas como técnica de pesquisa em enfermagem. Rev Latinoam Enferm. [Internet]. 2002 [citado em 23 jun 2020]; 10(3):423-32. Disponível em:
https://www.scielo.br/j/rlae/a/CfZzTLGbF 7qtpC9wGZT6YRc/?lang=pt

10. Minayo MCS. O desafio do conhecimento: pesquisa qualitativa em saúde. 14ed. São Paulo: Hucitec-Abrasco; 2014.

12. Demori CC, Prates LA, Alves CN, Wilhelm LA, Cremonese L, Castiglioni $\mathrm{CM}$, et al. O significado cultural da maternidade para mães adolescentes. Revista Interdisciplinar de Estudos em Saúde [Internet]. 2016 [citado em 23 jun 2020]; 5(1):46-56. Disponível em: https://periodicos.uniarp.edu.br/index.php/r ies/article/view/737

13. Santos NLB, Guimarães DA, Gama CAP. A percepção de mães adolescentes sobre seu processo de gravidez. Rev Psicol Saúde [Internet]. 2016 [citado em 23 jun 2020]; 8(2):83-96. Disponível em: http://pepsic.bvsalud.org/pdf/rpsaude/v8n2 /v8n2a07.pdf

14. Miura PO, Tardivo LSLP, Barrientos DMS. O desamparo vivenciado por mães adolescentes e adolescentes grávidas acolhidas institucionalmente. Ciênc Saúde Colet. [Internet]. 2018 [citado em 23 jun 2020]; 23(5):1601-10. Disponível em: https://www.scielo.br/j/csc/a/QdH37KmJz pTBYyTTwRnP5Ps/abstract/?lang=pt 15. Menezes GMD, Queiroz MVO, Pereira AS. Ações estratégicas do enfermeiro na linha do cuidado à adolescente grávida. Rev Enferm UFPE on line [Internet]. 2014 [citado em 23 jun 2020]; 8(4):927-36. Disponível em: https://periodicos.ufpe.br/revistas/revistaen fermagem/article/view/9762/9889

RECEBIDO: $15 / 01 / 2020$

APROVADO: 07/09/2020

PUBLICADO: 06/2021 